\title{
The year for our new endeavor: 2015
}

\section{Nagara Tamaki}

Published online: 1 October 2014

(C) Japan Radiological Society 2014

Thanks to the continuing support of the members of the editorial board, expert reviewers, and editorial team from Springer, the Japanese Journal of Radiology (JJR) is now making a good start in the year 2015 . This journal received over 500 submissions in 2014, a rate increase of $20 \%$. Approximately two-thirds of these manuscripts and half of the accepted articles come from countries outside of Japan, and these figures indicate that the JJR has become a really international journal.

In order to keep the publications in our journal timely, we have had to reject many good papers that did not reach certain standards for publication, and this made the acceptance rate low: approximately $20 \%$ in 2014 . On the other hand, the full-text downloads increased strikingly: $>40,000$ in 2013 and $>50,000$ in 2014. The impact factor also increased slightly: 0.646 in 2011, 0.730 in 2012, and 0.742 in 2013 . We awarded the most scientifically highquality paper, selected by editorial board members, and the most frequently cited paper at the Annual Meeting of the Japan Radiological Society in 2014, and we will continue to do so. We sincerely hope that such awards will help to attract high-quality papers to our journal.

As you can see, the journal contents have changed in the current issue. In addition to the original articles, we are now accepting well-focused review articles of high quality. We are also publishing letters to the editor in order to promote understanding of currently published topics through discussion of the recent publications. We also include guidelines made by the Society $[1,2]$. One in particular, dealing with the use of iodinated contrast media

N. Tamaki $(\bowtie)$

Department of Nuclear Medicine, Hokkaido University Graduate

School of Medicine, North 15, West 7, Kita-ku,

Sapporo 060-8638, Japan in patients with kidney disease, was the first attempt to describe the side effects of contrast media in various stages of kidney disease and its management; this was made possible by the collaboration of the committee members from the Japanese Society of Nephrology, Japanese Circulation Society, and Japan Radiological Society. The shorter version in the English language is available in the official journals of these societies [1]. We expect our readers will find the review articles, letters to the editors, and guidelines useful. Hopefully, such new endeavors will increase the number of downloads and the impact factor in the near future.

We are also making an effort to expand our readership throughout the world. With strong support of the Japan Radiological Society, the journal's table of contents has been widely disseminated to the members of related radiology societies worldwide. For instance, all the members of the Italian Society of Radiology can see the full contents of the JJR on their society home page, and at the same time, we, the members of the Japan Radiological Society, can see the full contents of the Italian journal. Through such activities, we would like to expand our readership throughout the world.

Because of our endeavor to promote the JJR as a highquality journal, we find accepting many case reports difficult. Since we are still publishing case reports, we receive many case report manuscripts; they actually constitute approximately half of all articles submitted to the JJR. Currently, the acceptance rate of case reports is quite low, approximately $14 \%$, compared to that of original articles, about $24 \%$. After long-term discussion about the scientific and educational value of case reports and the policy for handling them, we decided to accept only innovative and important cases that are worthy of publication [3, 4]. We would like to encourage those who plan to submit case 
report manuscripts to refer to our policy on case reports. As an official journal of the Japan Radiological Society, our policy of publication of an academic journal has always been the same as the aim of the society: promotion of radiology as science. We will continue to publish highquality research and strive to improve our patients' health and well-being. We are always happy to accept such articles, which are important for our readership.

We are deeply indebted to the many researchers and scientists who have contributed to the JJR by submitting their best work. We also express our sincere gratitude to the reviewers and editorial staff members who have dedicated their time and provided professional expertise to the journal. I am confident that this journal will continue to make important progress in 2015.

Nagara Tamaki, M.D., Editor-in-Chief

\section{References}

1. Ohno I, et al. Guidelines on the use of iodinated contrast media in patients with kidney disease 2012: digest version. Jpn J Radiol. 2013;31(4):546-84.

2. Miyayama S, et al. Guidelines on the use of gelatin sponge particles in embolotherapy. Jpn J Radiol. 2014;32(4):242-50.

3. Anonymous. Instruction to authors. Jpn J Radiol.

4. Ehara S. Assessing the scientific and educational value of case reports: an editor's view. Jpn J Radiol. 2011;29:1-2. 